Europe's Journal of Psychology, 8(1), pp. 182-202, doi:10.5964/ejop.v8i1.304 www.ejop.org

\title{
Freud's Conceptualization of the Social World: Psychology Recapitulating Sociology or Sociology Recapitulating Psychology?
}

Jonathan N. Stea

Department of Psychology, University of Calgary, Calgary, Canada

\section{Abstract}

This paper articulates Sigmund Freud's conceptualization of the social world by surveying and critically examining four of his major sociological works: Civilized' Sexual Morality and Modern Nervous Illness (Freud, 1908/1991b), Totem and Taboo (Freud, 1913/1946), The Future of An Illusion (Freud, 1927/1991d), and Civilization and Its Discontents (Freud, 1930/1991a). The paper also embeds the development of Freud's social theory within its historical context by discussing the impact of various evolutionary, philosophical, and life event influences. It is argued that Freud's social theory is merely a projection of his psychological theory of mind, which is predicated on the biogenetic principle (i.e., ontogeny recapitulates phylogeny). In tracing the development of Freud's social theory over time, an isomorphism is revealed whereby the changes in Freud's psychological thought reflect the changes in his social thought. In this way, Freud's sociology can be said to recapitulate his psychology despite Freud's insistence otherwise.

Keywords: Freud, psychoanalysis, psychology, sociology, social world.

Sigmund Freud is renowned for inventing the psychological paradigm of the mind known as psychoanalysis, which is acclaimed and revered by some, and denigrated and scorned by others. Indeed, it is fitting that opinions about psychoanalysis within the field of psychology are marked by ambivalence seemingly more than any other popular psychological theory. I contend that this ambivalence stems from the radical comprehensiveness of psychoanalysis, which Freud extended beyond the psychological and into the social realm. In a sense, psychoanalysis is a theory of everything. It is a story that depicts the state and development of the human condition spanning from prehistory to predictions about the future of civilization,

This is an open access article distributed under the terms of the Creative Commons Attribution License (http://creativecommons.org/licenses/by/3.0), which permits unrestricted use, distribution, and reproduction in any medium, provided the original work is properly cited. 
across the life-span, and from unconscious processes dwelling within the depths of the mind to conscious processes at the forefront of waking life.

This paper will navigate the vastness of psychoanalysis with the aim of extracting the core of Freud's social theory. In doing so, it will be necessary to embed Freud's social view within its theoretical and historical context in order to elucidate its origins. To accomplish this task, the paper will be composed of two sections. The first section will involve discussing how various evolutionary and philosophical ideas came to influence Freud's extension of his psychological theory to his social theory. In addition, relevant historical and personal life events will be discussed where it is believed that they impacted Freud's social theory.

In the second section of the paper, Freud's social worldview will be explicated with a view towards highlighting exactly how his conceptualization of the social world corresponds with his psychological theory. I will first draw upon and discuss four works that I believe provide the foundation for his social theory - namely, 'Civilized' Sexual Morality and Modern Nervous IIIness (Freud, 1908/1991b), Totem and Taboo (Freud, 1913/1946), The Future of An Illusion (Freud, 1927/1991d), and Civilization and Its Discontents (Freud, 1930/1991a). I then explicitly argue that Freud's social theory is merely a projection of his psychological theory, and as such, it assumes that the dynamics of the individual psyche are isomorphic with the dynamics of the social world. Moreover, it will be revealed that Freud's application of psychoanalysis to the social realm was uni-directional. That is, while Freud was adamant that his psychology recapitulated his sociology, it will become clear that his sociology in fact recapitulated his psychology. This latter point is not trivial; since Freud's sociology was borne out of his psychology and not vice versa, his sociology is not unique and is sustainable only insofar as the tenets (primarily the Oedipal process) of his psychology hold true.

\section{Historical and Theoretical Backdrop of Freud's Social Theory}

In order to understand Freud's conceptualization of the social world, it is necessary to understand the evolutionary principles, philosophical ideas, and life events that drove his theorizing. Thus, this section will highlight how these various influences anticipated and contributed to the development of Freud's social theory.

Evolutionary Influences

Freud's social theory was heavily influenced by the evolutionary climate of his time, and particularly by Jean-Baptiste Lamarck, Charles Darwin, and Ernst Haeckel (De 
Luca, 1977; Sulloway, 1982; Wallace, 1983). The biogenetic law - first propounded by the natural philosopher Carl Friedrich Kielmayer, endorsed by Darwin, and reinterpreted and popularized by Haeckel (Wallace, 1983) - is essentially the mechanism that Freud uses to expound his social theory. According to the biogenetic law advanced by Haeckel, ontogeny recapitulates phylogeny, or in other words, in man, the development from fetus to adulthood (i.e., ontogeny) is a brief recapitulation of the entire history of the race (i.e., phylogeny). Haeckel, the German apostle of Darwin (Wallace, 1983), believed that adult stages become modified by experience and that these modifications are then inherited and recapitulated at increasingly earlier stages in the descendants, such that ontogeny was thought to be a sort of memory for phylogeny - the experiences of which become condensed and abbreviated by ontogenetic repetition (Sulloway, 1982). Sulloway notes that in currently accepted Darwinian theory, however, there is no such recapitulation in the Haeckelian sense, as embryos are not miniature versions of ancestral adults but merely embryos that resemble one another more closely than adults simply because natural selection has acted far more intensely upon the adult states during the course of evolution thereby causing later stages, but not the embryos, to diverge. In the preface to the third edition (1915) of the Three Essays on the Theory of Sexuality (Freud, 1905/1953), Freud explicitly states his view of the biogenetic law:

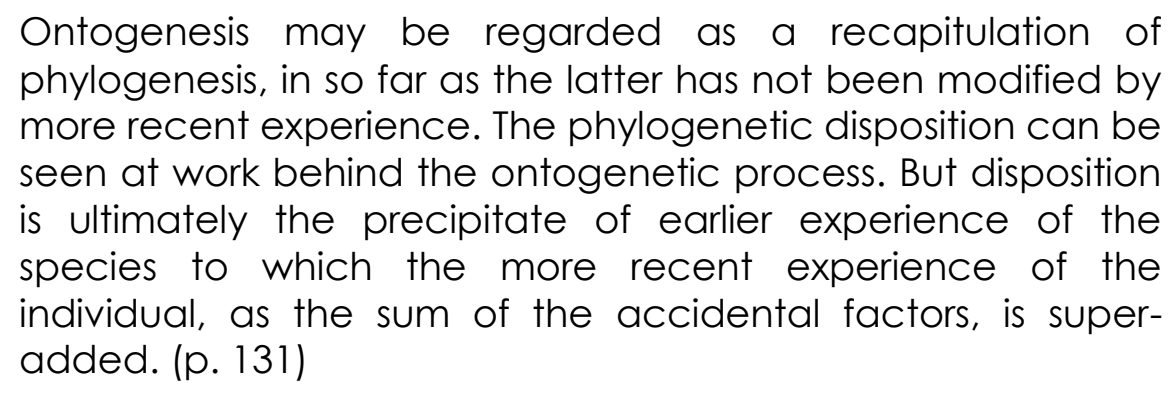

While it is believed that Freud read Haeckel, it is perhaps Darwin that exerted the most influence on Freud, as it is thought that Freud not only owned virtually every work by Darwin, but Darwin was also one of the few individuals that Freud was not shy to mention his intellectual indebtedness (De Luca, 1977; Wallace, 1983). As such, Darwin's Lamarckism and belief in the biogenetic law were particularly influential on Freud (Ritvo, 1965). In light of Lamarck's model, which allowed for the inheritance of acquired characteristics, Darwin thought it possible for humans to inherit quite complicated behavioral traits (e.g., idiosyncratic physical mannerisms and personal habits) as well as complex mental attributes (Wallace, 1983). The impact of Lamarckian and biogenetic thinking on Darwin is especially salient in his assertion that "every human brain passes in the course of its development through the same 
stages as those occurring in the lower vertebrate animals." (1872, as cited in Wallace, 1983, p. 245).

Freud's social theory was also indebted to several evolutionary anthropologists; there is direct evidence that he read John Lubbock, Herbert Spencer, and Edward Tylor, and a strong probability that he was familiar with the works of Lewis Morgan, John Ferguson McLennan, and Johann Jakob Bachofen (Wallace, 1983). According to Wallace, the views of these anthropologists had several fundamental notions in common. First, they believed that the history of human society is a development following very closely to one general law. Second, they presupposed man's psychic unity, the assumption of which is that the human mind works the same way in all individuals irrespective of various tribes and nations. Third, they espoused the doctrine of survivals, which essentially meant that processes, customs, opinions, and so forth, were carried on by force of habit into new societies different from that in which they had their original home, and thus they remained as proofs and exemplars of older cultures out of which newer ones evolved. Fourth, in line with their concept of survivals and their conviction that one could rank cultures on a scale of development, the anthropologists adopted the 'comparative method', which involved extrapolating from known stages of development in one culture to unknown stages in another. Finally, many of the anthropologists adhered to the Lamarckian notion of the transmission of cultural traits and the belief that the biogenetic law could be extended to psychic phenomena. Thus, Wallace argues that Freud was influenced by many of the ideas from these evolutionary thinkers, which is consistent with Freud's insistence throughout his career that "the phylogenetic foundation has ... the upper hand" (Freud, 1940/1964a, pp. 188-189), and by extension, his insistence that his psychology recapitulates his sociology.

Philosophical Influences

Wallace (1983) notes that at about the same time that Freud was reading Darwin, he was also reading the works of David Hume, Ludwig Andreas Feverbach, and Friedrich Nietzsche. These philosophers equipped Freud with the intellectual seeds that would help germinate not only his psychological theory but his social theory in particular. According to Wallace for example, in the Natural History of Religion (Hume, 1757, as cited in Wallace, 1983), Hume looked at his subject developmentally, viewed polytheism as the earliest stage of religion, thought that man conceived his deities as having qualities like himself, and viewed the origin of religion as stemming from passion, not curiosity. Similarly, Feverbach (1841, 1849, as cited in Wallace, 1983) viewed religion as a necessary stage in the development of man's self-consciousness, believed that religion everywhere preceded philosophy 
among both individuals and the human race, believed that animal worship everywhere preceded that of anthropomorphic deities, and saw religion as infantilism. In this way, both Hume and Feuerbach can be regarded as anticipating Freud's The Future of an Illusion.

Gay (1989, p. xxi) opines that Freud attempted to stay away from Nietzsche "precisely because he sensed how relevant" he was to his "terrain", which is consistent with Wallace's (1983) contention that there lurked some embarrassment on Freud's part at the many parallels (e.g., repression, sublimation, aggression, the unconscious) between his own work and Nietzsche's. Indeed, Wallace notes that by 1873, Freud had read everything Nietzsche had written up to that point. According to Wallace, like Hume, Nietzsche (1878, 1880, as cited in Wallace, 1983) also posited that religion arose in passion, whereby Nietzsche believed that on the basis of human needs and emotions, the human intellect caused the phenomenon of religion. Moreover, Wallace contends that Nietzsche anticipated Freud's Totem and Taboo insofar as Nietzsche viewed dreams and poetry as connected to primitive thought, and via his endorsement of the application of the biogenetic law to the psychic domain: "There must, too, be grooves and twists in our brains which answer to that [prehistoric] condition of mind, as in the form of certain human organs there are supposed to be traces of a fish-state." (Nietzsche, 1878, as cited in Wallace, 1983, pp. 63-64).

Life Event Influences

A few notable historical and personal life events are relevant to the development of Freud's social theory and therefore are worth highlighting. Wallace (1983) notes that Freud's infatuation with archaeology and ancient societies began in childhood and continued throughout his life; indeed, Freud was known to be an antiquity collector, and one-fifth of the titles in Freud's London library - which consisted only of what the Nazis allowed him to take - are on archaeology and ancient history (Wallace, 1983). Moreover, Wallace speculates that Freud's cultural consciousness may have been increased both by his ambivalent attitude towards his Jewish identity and by the growing Viennese anti-Semitism of his time. In this way, Freud's cultural interests and view of society were tainted by an interaction between his intellectual proclivities toward the study of archaeology and the political climate in which he lived.

Indeed, it has been suggested that the grim tone of Freud's Civilization and Its Discontents owes much to the growing power of Nazism both in Germany and in Austria; and that the final sentence in Civilization and Its Discontents, which was added by Freud in the second edition of 1931 (I quote this sentence later in the 
paper), may be understood to mirror Freud's dismay over the electoral triumph of Hitler's NSDAP in the elections to the German Reichstag the previous September (Gay, 1989). In addition, as Fancher (1998) suggests, the increasing philosophical and pessimistic tone of Freud's writing, as illustrated in The Future of an Illusion and Civilization and Its Discontents, might also have been influenced by the difficult fourteen remaining years of his life whereby he underwent a long series of painful and disfiguring operations as a result of being diagnosed with mouth cancer.

Finally, and interestingly, it has been suggested that Freud's Totem and Taboo was essentially an answer to Carl Gustav Jung. Schmidl (1952) explains that just prior to the publication of Totem and Taboo, Jung began publishing his deviating ideas from psychoanalysis, which included his view that the Oedipus phantasy was 'irreal' insofar that actual incest had never played any role in the history of mankind. Moreover, Jung explained the human psyche through myths, which precluded the search for the ultimate biological basis of the human psyche through the metaphysical postulate of a 'collective unconscious.' For Freud, this was a betrayal of psychoanalysis, and was unacceptable because he believed that an explanation of the basic qualities of man had to be based upon biology. In this way, Freud searched for the links that connected human history with biology and that connected the beginning of civilized society with prehistoric man, which he found in the myth of the primeval patricide. While it remains an assumption that Totem and Taboo is essentially a polemical book directed at Jung, it is at the very least likely that those of Freud's followers who were interested in religion, myth, and fairy tales (e.g., Otto Rank, Theodor Reik, and Carl Gustav Jung) served to influence the direction of his anthropological and sociological ideas (Schmidl, 1952).

\section{Summary}

It is in light of this historical and theoretical context that Freud became equipped with the intellectual framework to develop his social theory. Drawing from this framework, as will become apparent in the next section, it was Freud's belief in the biogenetic principle that was chiefly integral to his application of psychoanalytic theory to his social theory.

\section{Tracing the Development of Freud's Social Theory}

To Freud, psychoanalysis was clearly a social theory as well as a psychological theory. This section is dedicated to illustrating exactly how Freud's social theory corresponds to his psychological theory of the mind (i.e., psychoanalysis). I trace the development of Freud's social theorizing through four major works - namely, 
'Civilized' Sexual Morality and Modern Nervous Illness (Freud, 1908/1991b), Totem and Taboo (Freud, 1913/1946), The Future of An Illusion (Freud, 1927/1991d), and Civilization and Its Discontents (Freud, 1930/1991a) - and highlight along the way precisely how Freud predicates his social worldview on psychoanalysis. It should be noted that space precludes an exhaustive in-depth survey of all socially-relevant Freudian works, and as such, the works I have chosen to discuss center around macro-level social processes, such as the development and organization of culture, civilization, and religion. Thus, other important works that discuss micro-level social processes will not be discussed. For example, I will not touch upon Group Psychology and the Analysis of the Ego (Freud, 1921/1991c), which is concerned with interpersonal (cf., Being In Love and Hypnosis) and micro-group level processes (cf., Two Artificial Groups: The Church and The Army), nor will I discuss Moses and Monotheism (Freud, 1939/1964b), which is primarily concerned with leadership and does not offer anything new with respect to Freud's social theory (Wallace, 1977).

\section{'Civilized' Sexual Morality and Modern Nervous Illness}

Freud's first sociological exposition, entitled 'Civilized' Sexual Morality and Modern Nervous Illness, was first published in March, 1908 (Gay, 1989). In this work, Freud discusses for the first time at length the antagonism between civilization and instinctual life. To begin, Freud notes that his clinical observations had led him to differentiate between two groups of nervous disorders: the neuroses proper and the psychoneuroses. Importantly, the etiology of the neuroses proper (which Freud mentions are commonly grouped together as 'neurasthenia') is strictly sexual in nature and does not involve a "hereditary taint." In other words, these neuroses have nothing to do with civilization per se (the significance of which will become salient in a moment), and their etiology only involves disturbances or "injurious influences" that occur during sexual development or sexual life. On the other hand, with the psychoneuroses (e.g., hysteria and obsessional neurosis), Freud contends that "the influence of heredity is more marked and the causation less transparent" (p. 38), and that civilization may play a causal role by virtue of its influence in the suppression of sexual instincts:

They spring from the sexual needs of people who are unsatisfied and represent for them a kind of substitutive satisfaction. We must therefore view all factors which impair sexual life, suppress [italics added] its activity or distort its aims as being pathogenic factors in the psychoneuroses as well (p. 38).

The upshot of Freud's nervous disorder distinction is that suppression of the sexual instincts can result in psychoneuroses, and that this suppression is also precisely how 
civilization develops; and indeed, as articulated in Totem and Taboo, this suppression is partly responsible for the origins of civilization in the first place. Freud contends in 'Civilized' Sexual Morality and Modern Nervous Illness that "generally speaking, our civilization is built up on the suppression of instincts" (p. 38). When sexual instincts become suppressed, they find their expression either through the process of sublimation, which according to Freud is the "capacity to exchange . . sexual aim for another one, which is no longer sexual but which is psychically related to the first aim" (p. 39), or they exhibit an obstinate fixation, which renders them "unserviceable" and sometimes causes them to "degenerate into abnormities." Importantly, then, suppression of the sexual instincts may result in psychoneuroses (via the sexual instincts becoming fixated) or it may result in the pursuit of cultural activities and the development of civilization (via sublimation). According to Freud, the intensity of the sexual instincts and the proportion that is possible to sublimate are individual differences. In alluding to a machine that cannot indefinitely transform heat into mechanical energy, Freud notes that a person cannot sublimate indefinitely and must succumb to the hedonistic pleasure of the sexual instincts at least occasionally in order to avoid illness. However, Freud makes a case that finding this balance is a rarity; for reasons which will become clear in my discussion of Civilization and Its Discontents.

Thus, Freud raises the question as to "whether our 'civilized' sexual morality is worth the sacrifice which it imposes on us" (p. 55). In other words, Freud wonders whether the suppression of our sexual instincts, which on the one hand, serves to develop civilization by re-directing libidinal energy into productive cultural pursuits, and on the other hand, results in psychoneuroses that inevitably stifle those same cultural activities, is worth the return on investment.

It is noteworthy that 'Civilized' Sexual Morality and Modern Nervous Illness was devoted to describing the development and maintenance of civilization, as opposed to the origins of civilization, which Freud would go on to address in Totem and Taboo. In addition, 'Civilized' Sexual Morality and Modern Nervous Illness was devoted to explicating the antagonistic role of the sexual instincts, as opposed to the role of aggressive or destructive instincts. Interestingly, however, while in his Editor's Note (Freud, 1908/1991 b, pp. 29-31) Dickson maintains that Freud does not at all mention the aggressive instincts in 'Civilized' Sexual Morality and Modern Nervous Illness, close inspection reveals that Freud does indeed briefly foreshadow their role in the development of civilization, albeit the sexual instincts are given far more weight: 
Each individual has surrendered some part of his assets some part of the sense of omnipotence or of the aggressive or vindictive inclinations in his personality. From these contributions has grown civilization's common assets in material and ideal wealth. Besides the exigencies of life, no doubt it has been family feelings, derived from eroticism, that have induced the separate individuals to make this renunciation. The renunciation has been a progressive one in the course of the evolution of civilization. (p. 38-39)

Although no more regard is given to the aggressive instincts in the rest of 'Civilized' Sexual Morality and Modern Nervous Illness, the above passage shows that Freud was already beginning to contemplate their role in the development of civilization; which he would eventually elaborate on in great detail in Civilization and Its Discontents.

While 'Civilized' Sexual Morality and Modern Nervous Illness was Freud's first fulllength discussion of the antagonism between civilization and instinctual life, Dickson, in his Editor's Note (Freud, 1908/1991b, pp. 29-31), highlights that Freud was contemplating his application of psychoanalysis to the social realm much earlier. For instance, in a memorandum sent to his close friend Wilhelm Fliess on May $31^{\text {st }} 1897$, Freud contended that incest was anti-social and that civilization involved its progressive renunciation (Freud, 1897/1966). Similarly, in his paper Sexuality in the Aetiology of the Neuroses (Freud, 1898/1961b), Freud concluded that civilization could justifiably be regarded as partly responsible for the spread of neurasthenia; albeit not because of sexual suppression per se, but rather because contraception as a tool of civilization serves to impair sexual enjoyment and negatively impact sexual life, thereby causing illness. Finally, in his Three Essays on the Theory of Sexuality (Freud, 1905/1953), Freud spoke of the inverse relation between civilization and the free development of human sexuality.

Totem and Taboo

In the first three essays that compose Totem and Taboo - The Horror of Incest, Taboo and Emotional Ambivalence, and Animism, Magic and the Omnipotence of Thoughts - Freud presents cultural-anthropological, sociological, and psychological evidence to build a case for the argument he would present in his widely regarded controversial fourth and final essay. It is in this fourth essay, The Return of Totemism in Childhood (Freud, 1913/1989), that Freud explicitly launches his theory that the origins of "religion, morals, society and art converge in the Oedipus complex" (p. 510). 
Drawing explicitly from the work of J. G. Frazer, Charles Darwin, J. J. Atkinson, and his own clinical case formulations, Freud directly aims to use psychoanalysis to explain the origins of the two taboos of totemism: the law protecting the totem animal and the prohibition of incest. In constructing his argument, he first generalizes the findings from his phobic patient Little Hans (Freud, 1905/1955) and Sandor Ferenczi's phobic patient Little Arpad (as cited in Freud, 1913/1989) to conclude that the majority of animal phobias stem from a fear related to the father. Freud further invokes these cases to infer that it is common for people to displace their feelings from their father on to an animal, and that what typically follows is a projected ambivalent emotional attitude towards the animal (characterized by both hatred and affection), which culminates to identification with the animal. This psychological theory of the Oedipal process sets the stage for Freud's parricide hypothesis, which is essentially the foundation of his social theory.

The parricide hypothesis proposes the literal reenactment of the Oedipus complex by our ancestors. Freud contends that in the prehistoric primeval family, the brothers of the primal horde had initially been banished by the ruling father, who kept all of the females for himself. The brothers then banded together, killed, and devoured their father, which ended the patriarchal horde. By devouring the father, the brothers came to identify with him. In light of the ambivalence felt for the father, the brothers were overwhelmed by guilt over his murder. Out of this filial sense of guilt, the two taboos of totemism were created, which corresponded to the two repressed wishes of the Oedipus complex; that is, the repressed wish of sexual yearning for the mother corresponded with the exogamy rule and the repressed wish of wanting to kill the father corresponded with the rule governing protection of the totem. Freud then goes on to speculate about the development of the notion of God and Christianity (the ideas of which become more fully formed in The Future of An Illusion), and importantly, postulates that the unconscious memory and guilt over killing the father is inherited from generation to generation.

Interestingly, while Freud admits that his premises contain a great degree of uncertainty, he nevertheless is adamant that his literal depiction of the primeval Oedipal scene might have been an historical reality. He suggests that the minds of neurotics and primeval man are very similar in that they both "prefer psychic to factual reality and react just as seriously to thoughts as normal people do to realities" (p. 512). There is an important difference, however, between neurotics and primitive men:

But neurotics are above all inhibited in their actions: with them the thought is a complete substitute for the deed. 
Primitive men, on the other hand, are uninhibited: thought passes directly into action. With them it is rather the deed that is a substitute for the thought. And that is why, without laying claim to any finality of judgment, I think that in the case before us it may safely be assumed that 'in the beginning was the Deed.' (p. 513)

In addition to Freud's belief that the "Deed" actually took place, the corollary point that I am trying to make salient is that yet again, he draws upon his psychological theory (of the neurotic mind) in order to generate conclusions about primitive men, and consequently, the social world. Moreover, Freud essentially predicates the arguments made in Totem and Taboo on the biogenetic principle. He actually explicitly addresses this issue by stating "I have taken as the basis of my whole position the existence of a collective mind, in which mental processes occur just as they do in the mind of an individual" (p. 511). Freud further admits that "these are grave difficulties; and any explanation that could avoid presumptions of such a kind would seem to be preferable" (p. 511). That being said, he goes on to defend his position by asserting that it must be possible for psychical processes to continue from one generation to the next, or else social psychology in general could not exist.

The Future of An Illusion

While Totem and Taboo was concerned with explicating the roots of civilization, The Future of An Illusion was Freud's major work on religion as a contemporary social phenomenon. In this work, Freud likens religious ideas to powerful illusions that originate from the combination of both phylogenetically transmitted historical recollections (as outlined in Totem and Taboo) and the most pressing infantile wishes of mankind. These wishes, according to Freud, correspond to the yearning for protection through love from the father, which stem from the impression of helplessness in childhood. Importantly, Freud asserts that "the recognition that this helplessness lasts throughout life made it necessary to cling to the existence of a father, but this time a more powerful one" (p. 212). Thus, for Freud, religious ideas serve the function of a kind of mental protection provided by an illusory and powerful father figure.

The other crux to Freud's argument is that religion is the "universal obsessional neurosis of humanity; like the obsessional neurosis of children, it arose out of the Oedipus complex, out of the relation to the father" (p. 226). In other words, drawing upon his psychological theory, Freud contends that in the developmental process of resolving the Oedipus complex, children typically cannot progress to the "civilized stage" without first passing through a phase of neurosis. This is because the child cannot handle all of the instinctual demands placed upon him or her, and so these 
demands become tamed via the process of repression, which produces various forms of anxiety. Most of the neuroses are overcome spontaneously during the natural course of development, which Freud mentions is especially true for the obsessional neuroses of childhood. In this vein, Freud argues that in just the same way, humanity as a whole, in its development through the ages, fell into a state analogous to the childhood obsessional neurosis. Crucially, Freud asserts that in line with this typical developmental process, humanity should eventually resolve the Oedipus complex and consequently abandon religious beliefs:

If this view is right, it is to be supposed that a turning-away from religion is bound to occur with the fatal inevitability of a process of growth, and that we find ourselves at this very juncture in the middle of that phase of development. (p. 227)

Thus, in The Future of An Illusion, Freud extends his psychological theory to his social theory by means of diagnosing religion as an obsessional neurosis that parallels the experience of children during development. Here again, as in Totem and Taboo, Freud invokes the biogenetic law to argue that the ontogenetic Oedipus complex of the individual reflects the phylogenetic Oedipus complex of the human species. The biogenetic law also underlies the premise that the infantile wishes of the helpless individual child correspond to the wishes of the helpless human species.

\section{Civilization and Its Discontents}

In Civilization and Its Discontents, Freud explicitly returns to the theme of antagonism between the expression of primal instincts and the development and maintenance of civilization. He expounds a convoluted albeit vivid rendition of how his most recent contributions to psychoanalytic theory - namely, the superego and the death instinct and its derivatives (i.e., the aggressive and destructive instincts) - apply to his evolved social worldview. In updating his social theory, Freud begins in the first chapter by reiterating his message from The Future of An Illusion; namely that the origin of religious attitudes and beliefs can be clearly traced to the feeling of infantile helplessness.

In the second chapter, Freud argues that the purpose of life is to satisfy the pleasure principle, whereby he details a variety of ways that this can be achieved - such as via sublimation, illusions (e.g., satisfaction through art and beauty), and engulfment in love (including sexual gratification). Freud asserts that these activities essentially represent various ways to mitigate three sources of suffering: the deterioration of the body, ravages from the external world (e.g., natural disasters), and inadequate relations with other people (including lovers, friends, family, and society). In an 
attempt to avoid pain and neuroses as best as possible, Freud prescribes evenly distributing one's libidinal energy rather than placing all eggs in one basket, so to speak. Thus, for Freud, "happiness ... is a problem of the economics of the libido. There is no golden rule which applies to everyone: every man must find out for himself in what particular fashion he can be saved" (p. 271). Interestingly, Freud further comments that by virtue of religion forcing a state of psychic infantilism and mass-delusion, it serves to restrict one's path to the acquisition of happiness and protection from suffering, and consequently, it succeeds "in sparing many people an individual neurosis ... but hardly anything more" (p. 273).

Freud uses the third chapter to build upon his thoughts regarding the third source of human suffering (i.e., inadequate relations with other people). He suggests that "civilization is largely responsible for our misery" (p. 274) and devotes the rest of the chapter to describing the general nature of civilization. He contends that order and cleanliness are important requirements of civilization, and in this respect, he alludes to the development of anal eroticism in children and then points out the similarity between the process of civilization and the libidinal development of the individual child.

In chapter four, Freud refers to Totem and Taboo to introduce the notion that Eros (Love) and Ananke (Necessity) became the initial parents of civilization following the overthrow of the primal father. He further describes the function of Eros as serving to bind together considerable numbers of people, which civilization has ironically come to tame by virtue of restricting the sexual instincts of individuals. Even heterosexual genital love is restricted in the form of legitimacy and monogamy:

In no other case does Eros so clearly betray the core of his being, his purpose of making one out of more than one; but when he has achieved this in the proverbial way through the love of two human beings, he refuses to go further. (p. 298)

This antithesis between civilization and sexuality in particular was discussed in 'Civilized' Sexual Morality and Modern Nervous Illness.

To understand the cause of the antagonism between civilization and sexuality, Freud invokes the notion of the death instinct (the term 'Thanatos' is never actually employed by Freud in any of his works) in chapter five. He explains that the "inclination to aggression ... is the factor which disturbs our relations with our neighbor and which forces civilization into such a high expenditure [of energy]" ( $p$. 302). The aggressive instinct, which is a derivative of the death instinct, is responsible for the antagonism between civilization and sexuality because uninhibited sexuality would result in rampant competition, which would lead to ubiquitous aggressive 
activity. Freud thought that the instinctual passions were stronger than reasonable interests (i.e., common work and interests) and that civilization had to invest a tremendous amount of energy in order to set limits to man's aggressive instincts:

Hence, therefore, the use of methods intended to incite people into identifications and aim-inhibited relationships of love, hence the restriction upon sexual life, and hence too the ideal's commandment to love one's neighbour as oneself - a commandment which is really justified by the fact that nothing else runs so strongly counter to the original nature of man. (p. 303)

In this vein, the death instinct, in opposition to Eros, threatens to tear civilization apart. As such, civilization encourages the suppression (note that Freud is unclear about the distinction between suppression and repression) of both the sexual and aggressive instincts, albeit at the cost of man's happiness in exchange "for a portion of security" (p. 306).

In chapter six, Freud makes it explicitly clear that he is applying psychoanalysis to his conceptualization of the social world. He outlines how in Beyond the Pleasure Principle (Freud, 1920/1961a), his former distinction between ego-instincts and object-instincts became subsumed under the power of Eros, whereby 'libido' came to denote the energy of Eros in order to distinguish it from the energy (which incidentally was not given a label) of the death instinct. Civilization is considered to be "a process in the service of Eros, whose purpose is to combine single human individuals, and after that families then races, peoples and nations, into one great unity, the unity of mankind" (p. 313). The aggressive instinct acting as a derivative and representative of the death instinct is always in opposition to Eros, at both the individual and social level, rendering "the meaning of the evolution of civilization" a constant struggle "between the instinct of life and the instinct of destruction, as it works itself out in the human species" (p. 314).

The final two chapters are devoted to delineating how the superego serves as the mechanism that civilization employs in order to inhibit aggressiveness. Here again, Freud explicitly mentions that we can draw upon the history of the development of the individual in order to infer the process by which the superego exerts its effects. In the individual, aggressiveness is internalized and introjected back on to the ego, thereby re-directing the aggressive instinct energy. That is, the aggressive energy that was originally directed at other people is taken over by the agency of the superego, and in the form of 'conscience' (which Freud describes as the function of the superego), is ready to displace back on to the ego. The tension between the harsh superego and the ego generates 'the sense of guilt', which expresses itself as 
a need for punishment. In the same way, Freud describes epochs of civilizations as having their own superego (which he called the cultural superego), with the sense of guilt originating from the Oedipus complex, which was acquired at the killing of the father by the primal brothers (as described in Totem and Taboo).

Importantly, Freud contends that by means of the superego, it is the aggressive intention, not necessarily the act that invokes a sense of guilt. Thus, the effect of aggressive instinct renunciation on the conscience is that "every piece of aggression whose satisfaction the subject gives up is taken over by the superego and increases the latter's aggressiveness (against the ego)" (p. 321). This unconscious sense of guilt is phylogenetically transmitted to every individual as a result of the transmission of ambivalence surrounding the Oedipus complex. Crucially for Freud, the sense of guilt intensifies and strengthens as the community widens, since civilization is under the spell of Eros, which tries to erotically unite all human beings. As Eros widens its range, so too does the death instinct, and so too does the feeling of ambivalence originating from the Oedipus complex, which can be conceived of as extending from an individual's father to society at large. In other words, ambivalent affection and hatred stemming from the Oedipus complex, represented as Eros and the death instinct, respectively, is extended beyond the family, which necessarily increases the sense of guilt by virtue of amplifying aggressive wishes (originally confined to the father within the family) toward other people in society. In this vein, Freud asserts that the sense of guilt is the most important problem in the development of civilization in that "the price we pay for our advance in civilization is a loss of happiness through the heightening of the sense of guilt" (p. 327). At bottom, the sense of guilt coincides to fear of the superego, which results in a form of enduring anxiety produced by civilization that either remains to a large extent unconscious or manifests as a sort of malaise and general dissatisfaction.

In the final pages of the book, Freud acknowledges the similarity between psychoanalytic theory and his view of the social world. He contends, however, that one feature differs between the developmental process of the individual and the process of civilization. In the individual, the main aim is finding happiness, which is achieved via satisfaction of the pleasure principle. In contrast, the main aim of civilization is to create a unity between individual human beings. This difference, as Freud acknowledges, is not a struggle between the primal instincts of Eros and death but rather is a dispute within the economics of the libido, which concerns the distribution of libido between ego and objects. Freud states then, that "the developmental process of the individual can thus be expected to have special features of its own which are not reproduced in the process of human civilization" (p. 
334). As is clear, however, the main aim of civilization is still an application of Eros, which is a concept that is derived from Freud's psychology theory of the mind.

Finally, Freud concludes by suggesting that epochs of civilizations can become neurotic given the similarity between the development of civilization and the individual. However, he also warns that we should be cautious of the implications of communal neuroses given that "we are only dealing with analogies and that it is dangerous, not only with men but also with concepts, to tear them from the sphere in which they have originated and been evolved" (p. 338). Moreover, Freud acknowledges that with an individual neurosis, we have a benchmark of normality, which is absent in the case of communal neuroses. Thus, the fate of civilization is dependent upon Eros' ability to conquer the death instinct. Interestingly, in 1931, Freud added the following final sentence regarding Eros' aforementioned ability, which is apparently reflective of his increasing pessimism surrounding the menace of Hitler: "But who can foresee with what success and with what result?" (p. 340)

\section{Isomorphism of Freud's Social Theory}

From the previous discussions, it is clear that Freud was conspicuously applying psychoanalytic theory to his conceptualization of the social world. Indeed, Freud was not hiding the fact that he thought concepts such as the Oedipus complex, neuroses, and the superego were social as well as psychological. These concepts operated in exactly the same way at both the social and psychological levels. As such, despite the fascinating implications, I contend that Freud's social worldview is merely an application of psychoanalysis that is contingent upon the success of the biogenetic principle. That is, without Freud's prehistoric reification of the Oedipus complex and its phylogenetic transmission, the entirety of Freud's social theory falls apart. The Oedipal process occurring at the social level is responsible for the origins, development, and maintenance of macro-level social processes, including religion, culture, and civilization. Thus, Freud's social theory is not unique insofar as it merely represents psychoanalytic principles operating at the social level of analysis. In this vein, despite Freud's insistence otherwise, his sociology is in fact a recapitulation of his psychology.

To somewhat digress briefly, it is interesting that in 1983, a lost paper that Freud wrote on July 28, 1915 entitled the Overview of the Transference Neuroses was discovered in a trunk which belonged to Sandor Ferenczi (see Silverstein, 1989). In this paper, Silverstein explains that Freud first warned his audience that his ideas were not confirmed, and then he presented a 'phylogenetic fantasy' whereby he speculated that the development of individual psychopathology corresponded to a biogenetic 
series. That is, psychological disorders purportedly recapitulated a stage in the history of human civilization: anxiety hysteria was related to economizing libido during the Ice Age; conversion hysteria, to the need to limit overpopulation; obsessional neurosis, to the appearance of the primal horde; dementia praecox, to the pressure from the primal father to relinquish all sexual objects; paranoia, to the struggle against homosexuality instituted by the primal father; melancholia, to remorse over the killing of the primal father; and mania, to identification with the primal father. This digression (both mine and Freud's) attests to Freud's conviction regarding the biogenetic law and its influence on his thinking (Wallace, 1983).

In any event, not only is it clear that Freud intended to apply psychoanalytic principles to his social theory, but in surveying the works discussed above, it becomes evident that his application of psychoanalysis was isomorphic with his social theorizing. In other words, as Freud's psychological theory of the mind evolved over time, so too did his social theory in a correspondingly strict fashion. This isomorphism is particularly salient when one considers that 'Civilized' Sexual Morality and Modern Nervous Illness was originally published in 1908 and was therefore written within the framework of Freud's topographical model of the mind; whereas Civilization and Its Discontents was originally published in 1930, and was based on Freud's structural theory of the mind, which he most concretely espoused in 1923 with the publication of The Ego and the Id (Freud, 1923/1961C). Moreover, it was only after the publication of Beyond the Pleasure Principle in 1920 that Freud incorporated notions of the love and death instincts into his social theory.

Interestingly, close inspection of Totem and Taboo reveals the seeds of what was to become Freud's concept of the superego:

Thus after a long lapse of time their bitterness against their father, which had driven them to their deed, grew less, and their longing for him increased; and it became possible for an ideal to emerge which embodied the unlimited power of the primal father against whom they had once fought as well as their readiness to submit to him. (p. 505)

Again, however, the superego per se was never formally invoked in Freud's social theorizing until after the publication of The Ego and the Id.

Cavalletto (2007) notes a chronological puzzle in Freud's work. Although The Future of An Illusion and Civilization and Its Discontents were published only two years apart (as Civilization and Its Discontents was originally published in 1929, despite the 1930 version in my References section), they appear to be products of different theoretical mindsets. The Future of An Illusion invoked the terms of Freud's first theory 
of the instincts, which resulted in cultural manifestations of unconscious wishes and instinctual desires - thoughts that are reminiscent of 'Civilized' Sexual Morality and Modern Nervous Illness and in general, Freudian theorizing from 1905 to 1917. In contrast, as was previously mentioned, Civilization and Its Discontents invoked Freud's structural theory of the mind and his more recent theory of instincts involving the battle of Eros against death. Cavalletto suggests that the reason Freud ignored radical revisions to his theory and retreated to the earliest stages of his thinking in The Future of An Illusion is because Freud distrusted system building, so to speak. That is, he often adopted new ideas while at the same time remained attached to older, no longer fully compatible ones. In this sense, Freud followed a patchwork method of conceptualization, which one might argue renders him a true evolutionist!

Of course, the biggest problem with Freud's adherence to the assumption that the dynamics of the individual mind correspond to the dynamics of macro-level social processes is that Freud would have a difficult time not only explaining the radical diversity between religions, cultures, and civilizations, but also the diversity within them. Indeed, just as Freud's psychological theory assumes psychic unity across individuals, his social theory assumes a kind of social unity across time, religions, cultures, and civilizations. Wallace (1983) argues that Freud can only apply psychoanalysis to the social realm metaphorically, and that for the most part, it is only with the smallest and most homogenous societies that a 'group unconscious' might retain any meaning.

Finally, by virtue of Freud's social theory mirroring his psychological theory, an illusion of credence is given to psychoanalysis. In other words, Freud's social theory might be regarded as a red herring insofar as criticisms that are launched towards it should really be aimed at his psychological theory if they wish to be effective (for criticisms against his social theory, see Wallace, 1983). In this sense, Freud's social theorizing merely furnishes and buttresses psychoanalysis, albeit redundantly.

\section{Conclusions}

Freud's social worldview was very much the product of the historical context in which it was developed, which consisted of the interplay between Freud's theoretical influences, personal life events, and cultural and political climate. These influences served to shape the formation of psychoanalysis in general and facilitated its extension to the social realm. By tracing the corresponding vicissitudes of Freud's psychological and social thought, it becomes evident that his conceptualization of the social world was merely a uni-directional projection of psychoanalysis, which was predicated on the biogenetic principle. This isomorphism was problematic because 
it rendered Freud's psychological and social theories vulnerable to the same set of criticisms. Nevertheless, psychoanalysis was destined to invade other academic disciplines (Gay, 1989, p. xxii), and I contend that its strength is demonstrated in part by this ability to reach beyond psychology into other domains of inquiry.

\section{Acknowledgements}

I thank Dr. Henderikus J. Stam for his kind words and suggestions for how to improve this manuscript.

\section{References}

Cavalletto, G. (2007). Crossing the psycho-social divide: Freud, Weber, Adorno and Elias. Aldershot: Ashgate.

De Luca, A. J. (1977). Freud and future religious experience. New York: Philosophical Library Inc.

Fancher, R. E. (1998). Commentary on "The origin and development of psychoanalysis." Retrieved October 15, 2009, from http://psychclassics.yorku.ca/Freud/Origin/commentary.htm

Freud, S. (1946). Totem and taboo: Resemblances between the psychic lives of savages and neurotics (A. A. Brill, Trans.). New York: Vintage. (Original work published 1913)

Freud, S. (1953). Three essays on the theory of sexuality. In J. Strachey (Ed.), The standard edition of the complete psychological works of Sigmund Freud (Vol. 7, pp. 130-243). London: The Hogarth Press. (Original work published 1905)

Freud, S. (1955). Analysis of a phobia in a five-year-old boy. In J. Strachey (Ed.), The standard edition of the complete psychological works of Sigmund Freud (Vol. 10, pp. 1-147). London: The Hogarth Press. (Original work published 1909)

Freud, S. (1961a). Beyond the pleasure principle. In J. Strachey (Ed.), The standard edition of the complete psychological works of Sigmund Freud (Vol. 18, pp. 1-64). London: The Hogarth Press. (Original work published 1920) 
Freud, S. (1961b). Sexuality in the aetiology of the neuroses. In J. Strachey (Ed.), The standard edition of the complete psychological works of Sigmund Freud (Vol. 3, pp. 261-285). London: The Hogarth Press. (Original work published 1898)

Freud, S. (1961c). The ego and the id. In J. Strachey (Ed.), The standard edition of the complete psychological works of Sigmund Freud (Vol. 19, pp. 12-66). London: The Hogarth Press. (Original work published 1923)

Freud, S. (1964a). An outline of psycho-analysis. In J. Strachey (Ed.), The standard edition of the complete psychological works of Sigmund Freud (Vol. 23, pp. 144-207). London: The Hogarth Press. (Original work published 1940)

Freud, S. (1964b). Moses and monotheism. In J. Strachey (Ed.), The standard edition of the complete psychological works of Sigmund Freud (Vol. 23, pp. 7-137). London: The Hogarth Press. (Original work published 1939)

Freud, S. (1966). Fliess correspondence, draft N. In J. Strachey (Ed.), The standard edition of the complete psychological works of Sigmund Freud (Vol. 1, pp. 254-256). London: The Hogarth Press. (Original work published 1897)

Freud, S. (1989). The return of totemism in childhood. In P. Gay (Ed.), The Freud reader (pp. 482-513). New York: Norton. (Original work published 1913)

Freud, S. (1991 a). Civilization and its discontents. In A. Dickson (Ed.), Civilization, society and religion: Group psychology, civilization and its discontents and other works (Vol. 12, pp. 244-340). London: Penguin Books. (Original work published 1930)

Freud, S. (1991b). 'Civilized' sexual morality and modern nervous illness. In A. Dickson (Ed.), Civilization, society and religion: Group psychology, civilization and its discontents and other works (Vol. 12, pp. 29-55). London: Penguin Books. (Original work published 1908)

Freud, S. (1991c). Group psychology and the analysis of the ego. In A. Dickson (Ed.), Civilization, society and religion: Group psychology, civilization and its discontents and other works (Vol. 12, pp. 91-178). London: Penguin Books (Original work published 1921).

Freud, S. (1991d). The future of an illusion. In A. Dickson (Ed.), Civilization, society and religion: Group psychology, civilization and its discontents and other works (Vol. 12, pp. 179- 241). London: Penguin Books. (Original work published 1927)

Gay, P. (Ed.). (1989). The Freud reader. New York: Norton. 
Ritvo, L. B. (1965). Darwin as the source of Freud's neo-Lamarckism. Journal of the American Psychoanalytic Association, 13, 499-517. doi:10.1177/000306516501300302

Schmidl, F. (1952). Freud's sociological thinking. Bulletin of the Menninger Clinic, 16, $1-13$.

Silverstein, B. (1989). Oedipal politics and scientific creativity: Freud's 1915 phylogenetic fantasy. Psychoanalytic Review, 76, 403-424.

Sulloway, F. J. (1982). Freud and biology: The hidden legacy. In W. R. Woodward \& M. G. Ash (Eds.), The problematic science: Psychology in nineteenth-century thought (pp. 198-227). New York: Praeger Publishers.

Wallace, E. R., IV. (1977). The development of Freud's ideas on social cohesion. Psychiatry, 40, 232-241.

Wallace, E. R., IV. (1983). Freud and anthropology: A history and reappraisal. New York: International University Press

\section{About the author}

Jonathan N. Stea is a PhD Candidate in the Clinical Psychology program at the University of Calgary, Canada. His primary research interests include topics that focus on the etiology and determinants of addiction-related disorders.

Address for correspondence: Jonathan N. Stea, Department of Psychology, University of Calgary, 2500 University Drive NW, T2N 1N4, Calgary, Alberta, Canada. E-mail: jnstea@ucalgary.ca 